\title{
Photochemical H2 Evolution Using a Ru-Rh Supramolecular Photocatalyst
}

Debashis Ghosh, ${ }^{* 1,2}$ David C. Fabry, ${ }^{1}$ Daiki Saito ${ }^{1}$ and Osamu Ishitani*1

${ }^{1}$ Department of Chemistry, School of Science, Tokyo Institute of Technology, 2-12-1-NE-1, Ookayama, Meguro-ku, Tokyo, 152-8550, Japan

${ }^{2}$ Department of Chemistry, St. Joseph's College (Autonomous), Bangalore-560027, Karnataka, India

Corresponding Authors

Debashis Ghosh*

Email: deba.kamarpukur@gmail.com

Osamu Ishitani*

Email: ishitani.o.aa@m.titech.ac.jp

\section{Contents of the Supporting Information}

Total no of pages: 12

Total no of figures: 14 

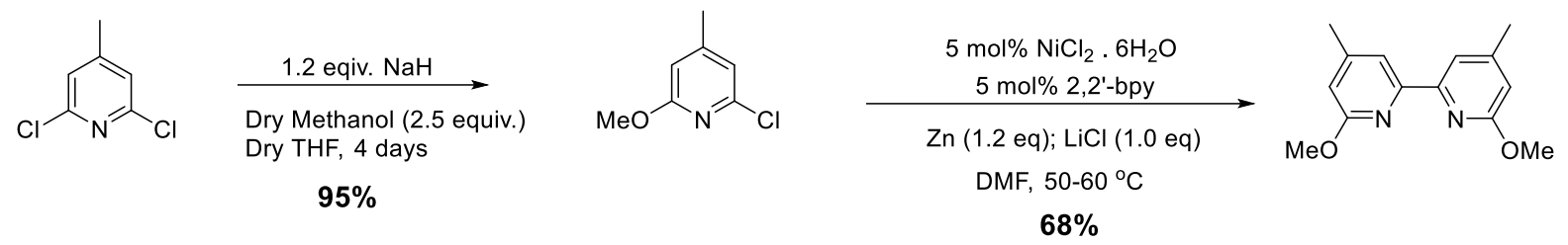

Scheme S1. Synthesis of 6,6'-dimethoxy-4,4'-dimethyl-2,2'-bipyridine. Percentages represent yield

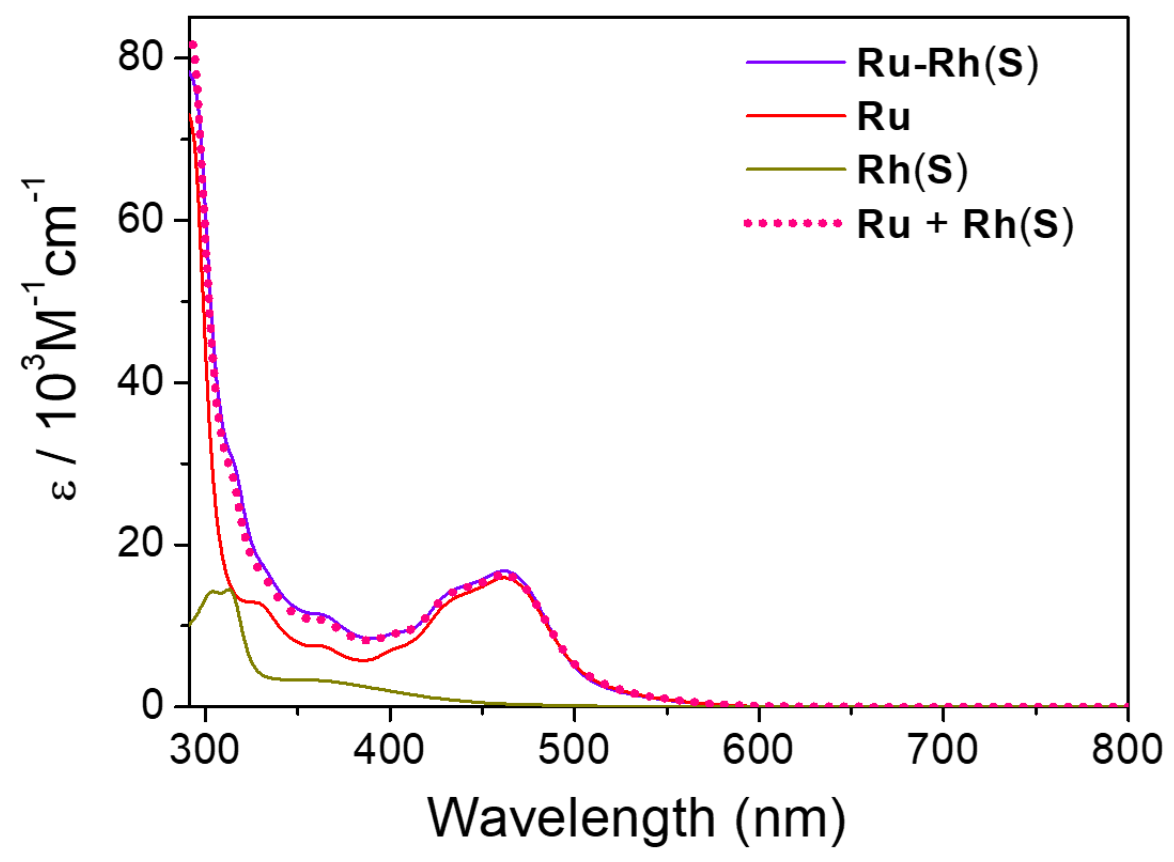

Figure S1. UV-vis absorption spectra of ruthenium and rhodium complexes, $\mathbf{R u}-\mathbf{R h}(\mathbf{S})$ (violet), $\mathbf{R u}$ (red), $\mathbf{R h}(\mathbf{S})$ (dark yellow) measured in DMA. The dotted line shows the 1:1 summation spectrum of $\mathbf{R u}$ and $\mathbf{R h}(\mathbf{S})$. 


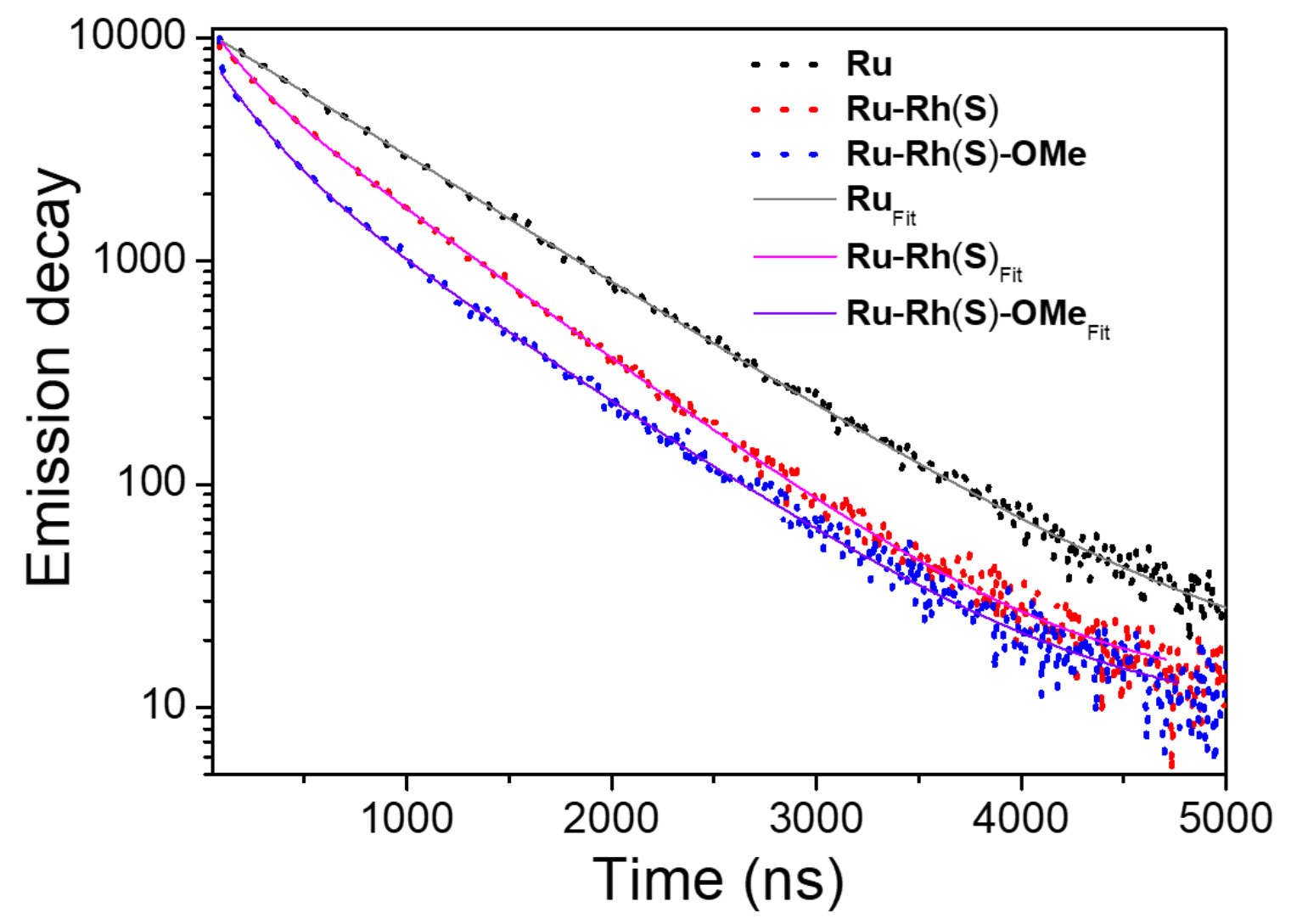

Figure S2. Emission decay of the Ru (dark yellow), $\mathbf{R u}-\mathbf{R h}(\mathbf{S})$ (red) and $\mathbf{R u}-\mathbf{R h}(\mathbf{S})-\mathbf{O M e}$ (blue) complexes in Ar-saturated DMA at $298 \mathrm{~K}$ with irradiation at $\lambda_{\mathrm{ex}}=456 \mathrm{~nm}$ with FluoroHub timecorrelated single photon counting system under deaerated (using freeze-pump-thaw method; three times) conditions at room temperature. The solid lines show the fitting results.
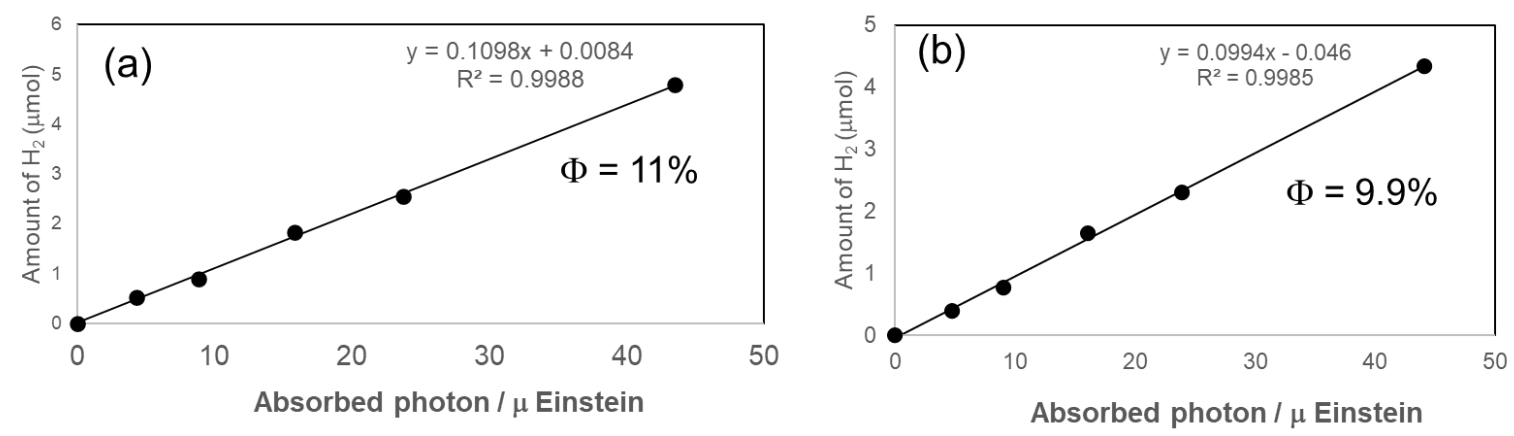

Figure S3. Figures (a) and (b) show formation quantum yield ( $\Phi)$ of $\mathrm{H}_{2}$ for $\mathbf{R u}-\mathbf{R h}(\mathbf{S})-\mathbf{O M e}(0.05$ $\mathrm{mM})$ using mixture of $\mathrm{BIH}(0.1 \mathrm{M})$ and $3,5-\mathrm{F}_{2}-\mathrm{PhOH}(0.1 \mathrm{M})$ and $\mathrm{BI}(\mathrm{OH}) \mathrm{H}(0.1 \mathrm{M})$, respectively under Ar (light intensity $=3.5 \times 10^{-9} \mathrm{E} \mathrm{s}^{-1}$ ). 


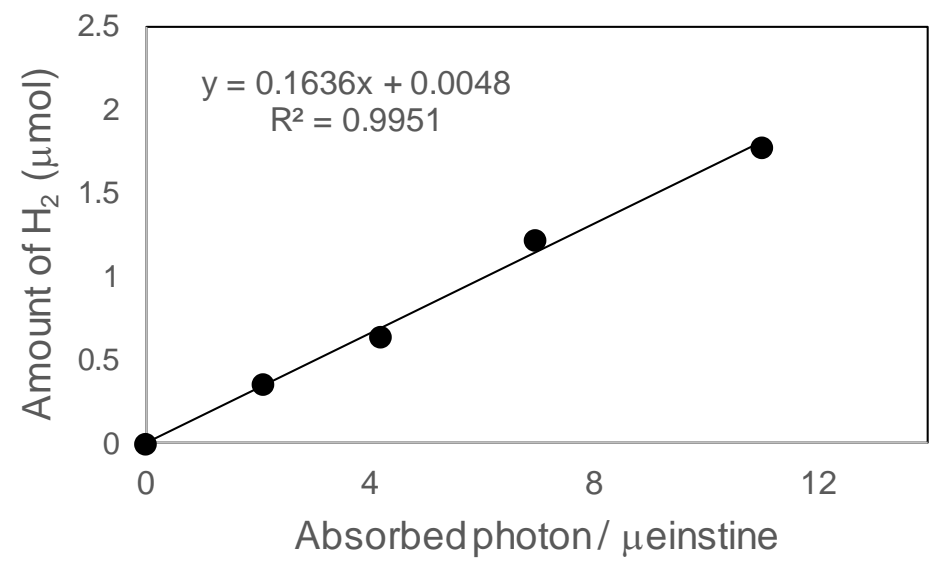

Figure S4. Formation quantum yield $(\Phi)$ of $\mathrm{H}_{2}$ for $\mathbf{R u}-\mathbf{R h}(\mathbf{S})-\mathbf{O M e}(0.05 \mathrm{mM})$ under $\mathrm{CO}_{2}$ (light intensity $=3 \times 10^{-9} \mathrm{E} \mathrm{s}^{-1}$ ).

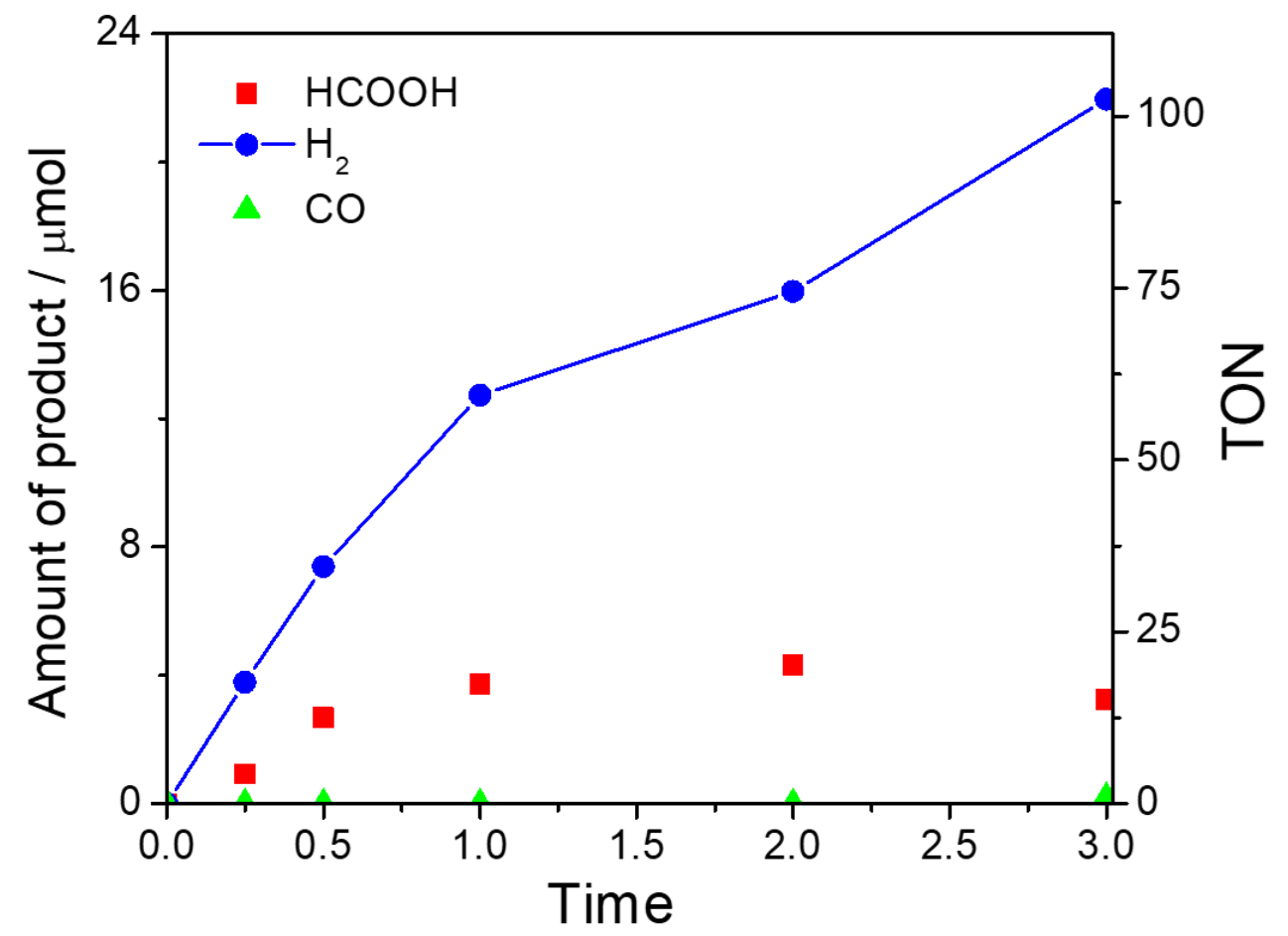

Figure S5. Time dependences of $\mathrm{HCOOH}(\boldsymbol{\bullet}), \mathrm{H}_{2}(\bullet)$ and $\mathrm{CO}(\boldsymbol{\Delta})$ formation during the irradiation to a $\mathrm{CO}_{2}$-saturated DMA-TEOA $(4: 1 \mathrm{v} / \mathrm{v}, 4.0 \mathrm{~mL})$ solution containing $\mathbf{R u}(0.05 \mathrm{mM})$ and $\mathbf{R h}(\mathbf{S})$ OMe $(0.05 \mathrm{mM})$ at $\lambda_{\text {ex }}=480 \mathrm{~nm}$ (light intensity $=3.5 \times 10^{-8}$ einstein $\left.\mathrm{s}^{-1}\right)$ in the presence of BIH $(0.1 \mathrm{M})$. 


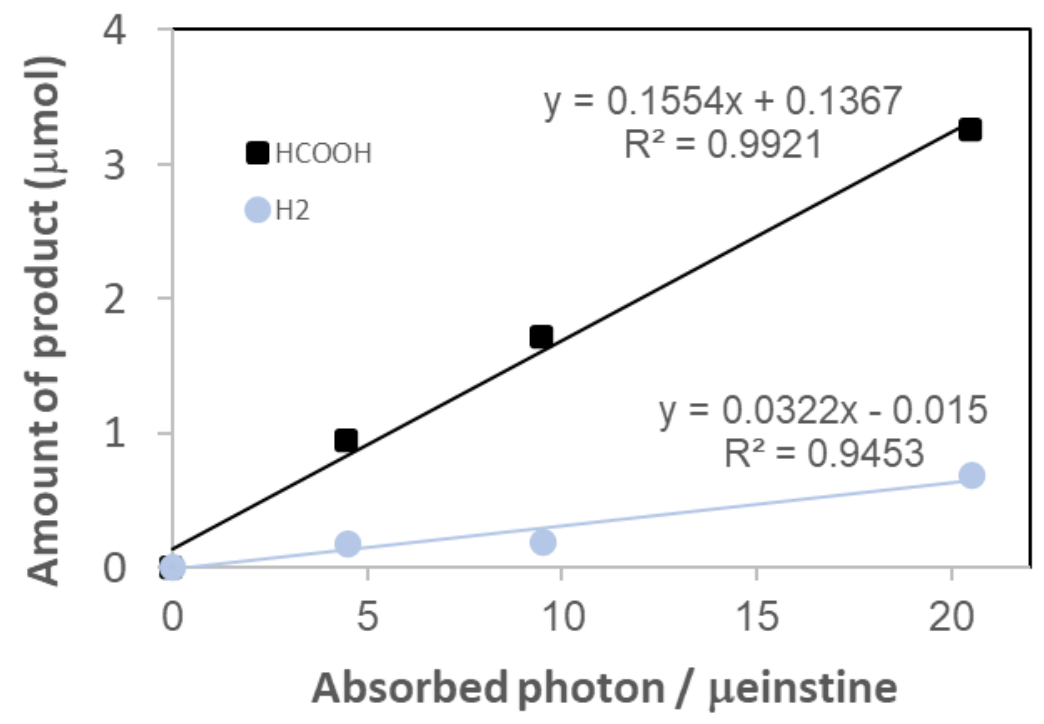

Figure S6. Formation quantum yield $(\Phi)$ of $\mathrm{HCOOH}$ and $\mathrm{H}_{2}$ for $\mathbf{R u}-\mathbf{R h}(\mathbf{S})-\mathbf{O M e}(0.05 \mathrm{mM})$ under $\mathrm{CO}_{2}$ (light intensity $=3.0 \times 10^{-9} \mathrm{E} \mathrm{s}^{-1}$ ).
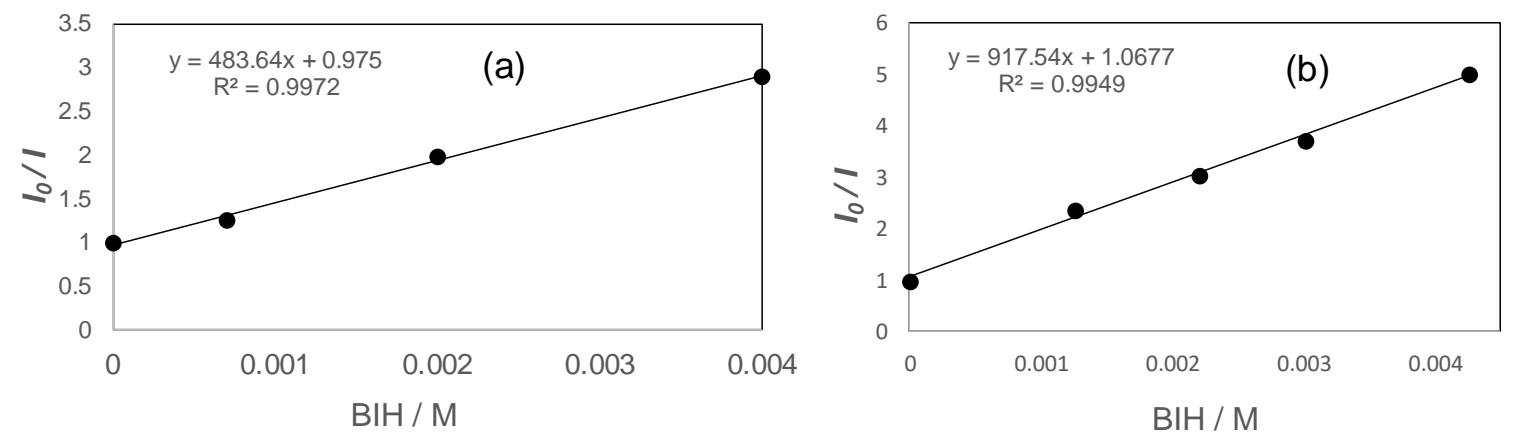

Figure S7. Stern-Volmer plots for emission quenching of $\mathbf{R u - R h}(\mathbf{S})-\mathbf{O M e}$ (a) and $\mathbf{R u}-\mathbf{R h}(\mathbf{S})$ (b) by BIH in DMA-TEOA (4:1 v/v) mixed solutions at $298 \mathrm{~K}$ after degassing with Ar. 

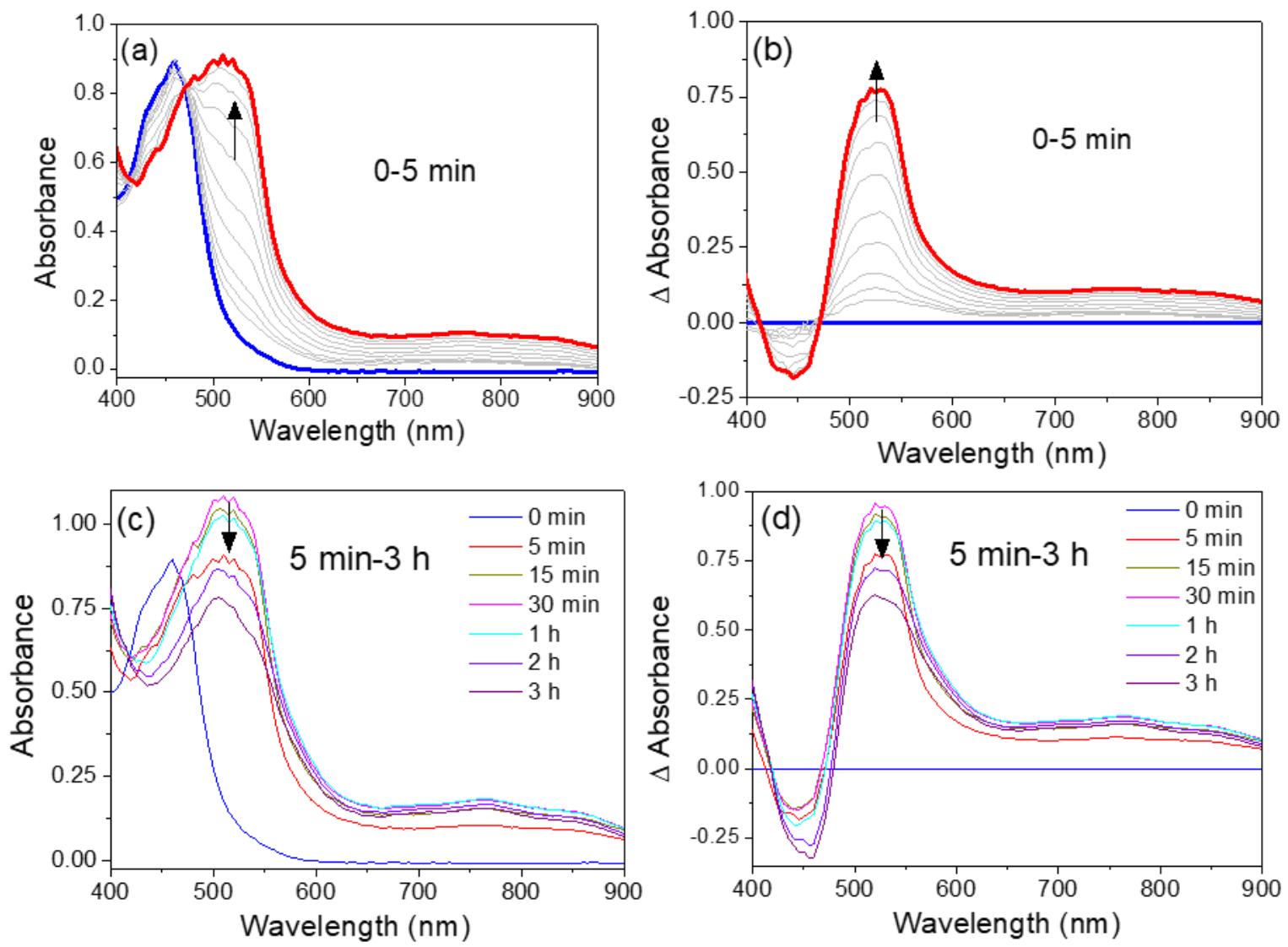

Figure S8. UV-vis and differential UV-vis absorption spectral changes of $\mathbf{R u}-\mathbf{R} \mathbf{h}(\mathbf{S})$ during irradiation under $\mathrm{Ar}$ in the presence of $\mathrm{BIH}$ : at initial stage (irradiation time: $0-5 \mathrm{~min}$ at $30 \mathrm{~s}$ intervals, red after $5 \mathrm{~min}$ ) (a), (b) and in later stage (irradiation time: $5 \mathrm{~min}-3 \mathrm{~h}$, purple after $3 \mathrm{~h}$ ) (c), (d), respectively. Photochemical reaction conditions were the same as mentioned in Table 3, manuscript. 

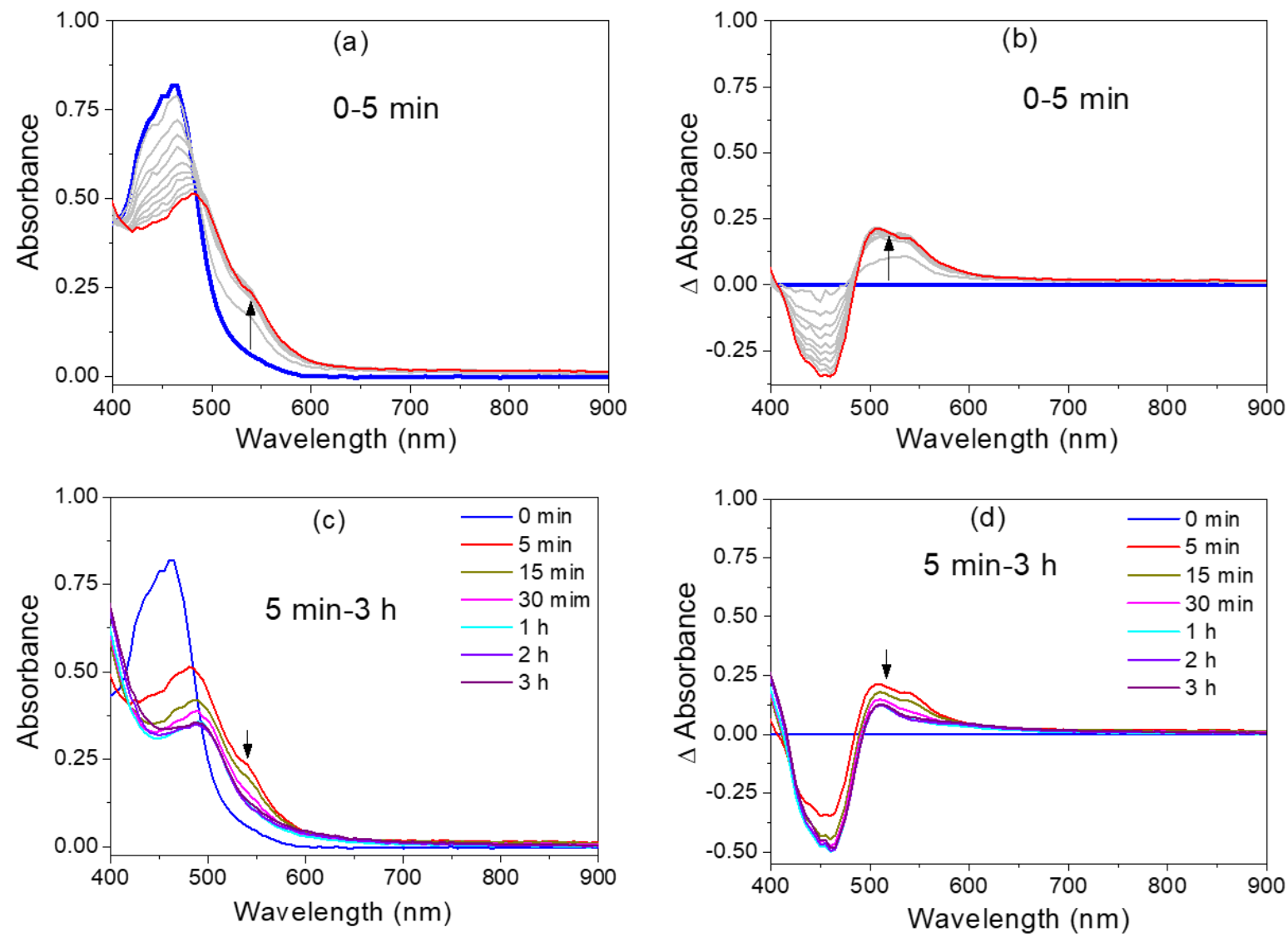

Figure S9. Time dependent UV-vis and differential UV-vis absorption spectra of $\mathbf{R u - R h ( S ) - O M e}$ during irradiation under $\mathrm{Ar}$ in the presence of mixture of $\mathrm{BIH}$ and 3,5- $\mathrm{F}_{2}-\mathrm{PhOH}$ : at initial stage (0-5 min at $30 \mathrm{~s}$ intervals; red after $5 \mathrm{~min})(\mathrm{a}),(\mathrm{b})$ and later stage $(5 \mathrm{~min}-3 \mathrm{~h}$; purple after $3 \mathrm{~h})$ (c), (d), respectively. Photo chemical reaction condition was same as mentioned in entry 2, Table 3 , manuscript. 

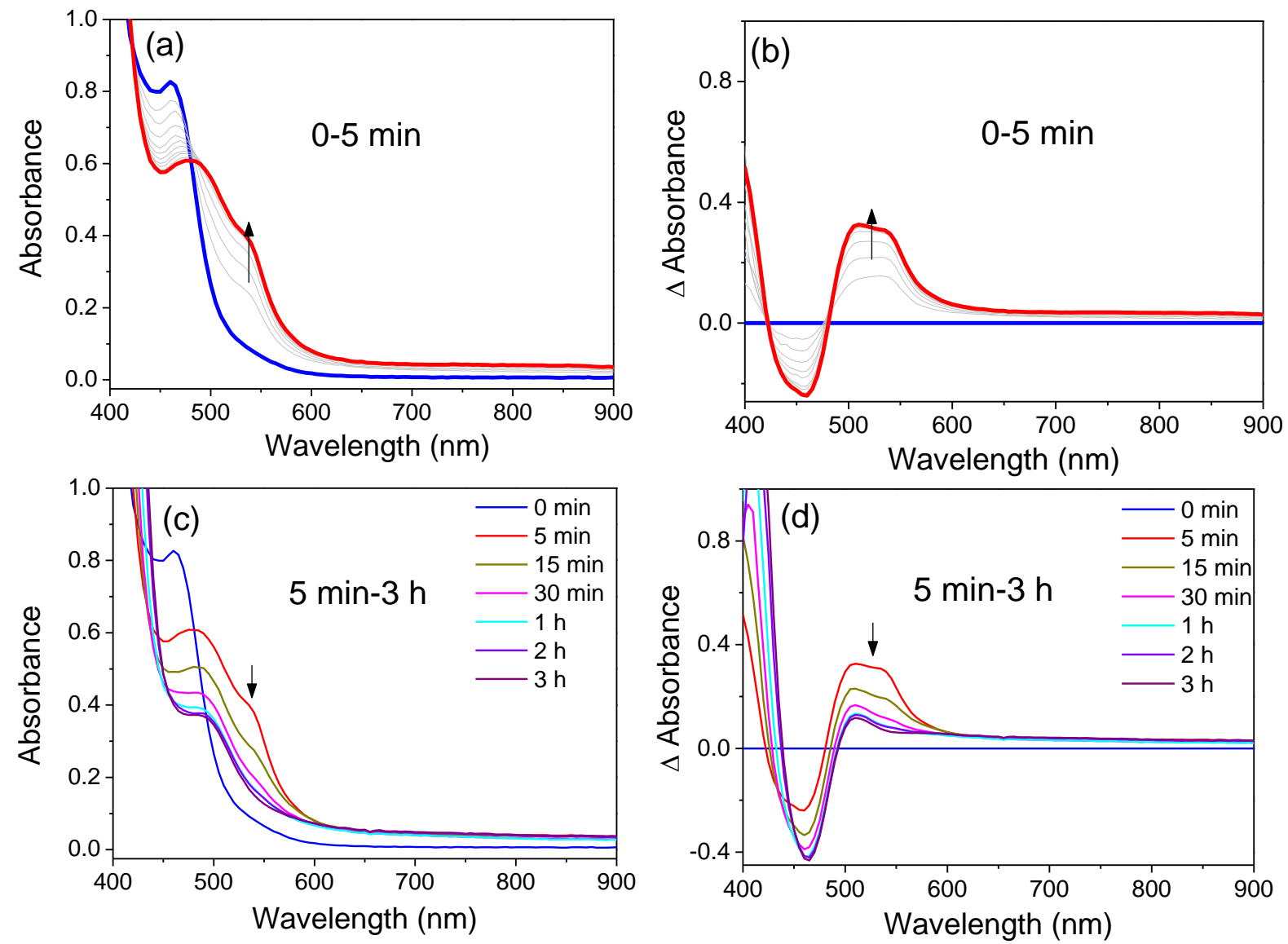

Figure S10. Time dependent UV-vis and differential UV-vis absorption spectra of $\mathbf{R u}-\mathbf{R h}(\mathbf{S})$ OMe during irradiation under $\mathrm{Ar}$ in the presence of $\mathrm{BI}(\mathrm{OH}) \mathrm{H}$ : at initial stage $(0-5 \mathrm{~min}$ at $30 \mathrm{~s}$ intervals; red after $5 \mathrm{~min}$ ) (a), (b) and later stage (5 min $-3 \mathrm{~h}$; purple after $3 \mathrm{~h}$ ) (c), (d), respectively. Photo chemical reaction condition was same as mentioned in entry 3 , Table 3 , manuscript. 


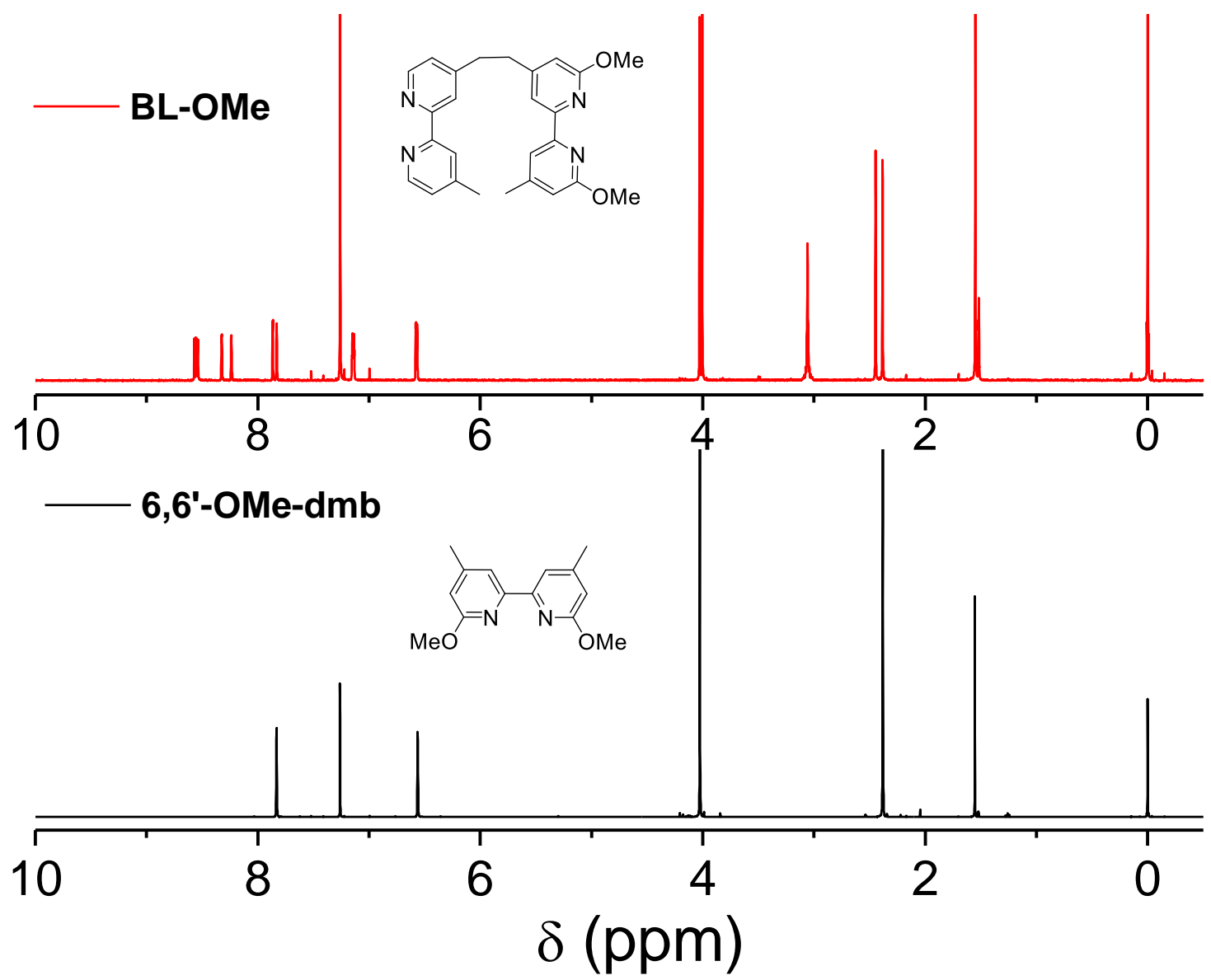

Figure S11: ${ }^{1} \mathrm{H}$ NMR spectrum of 6,6'-OMe-dmb and BL-OMe taken in $\mathrm{CDCl}_{3}$. 


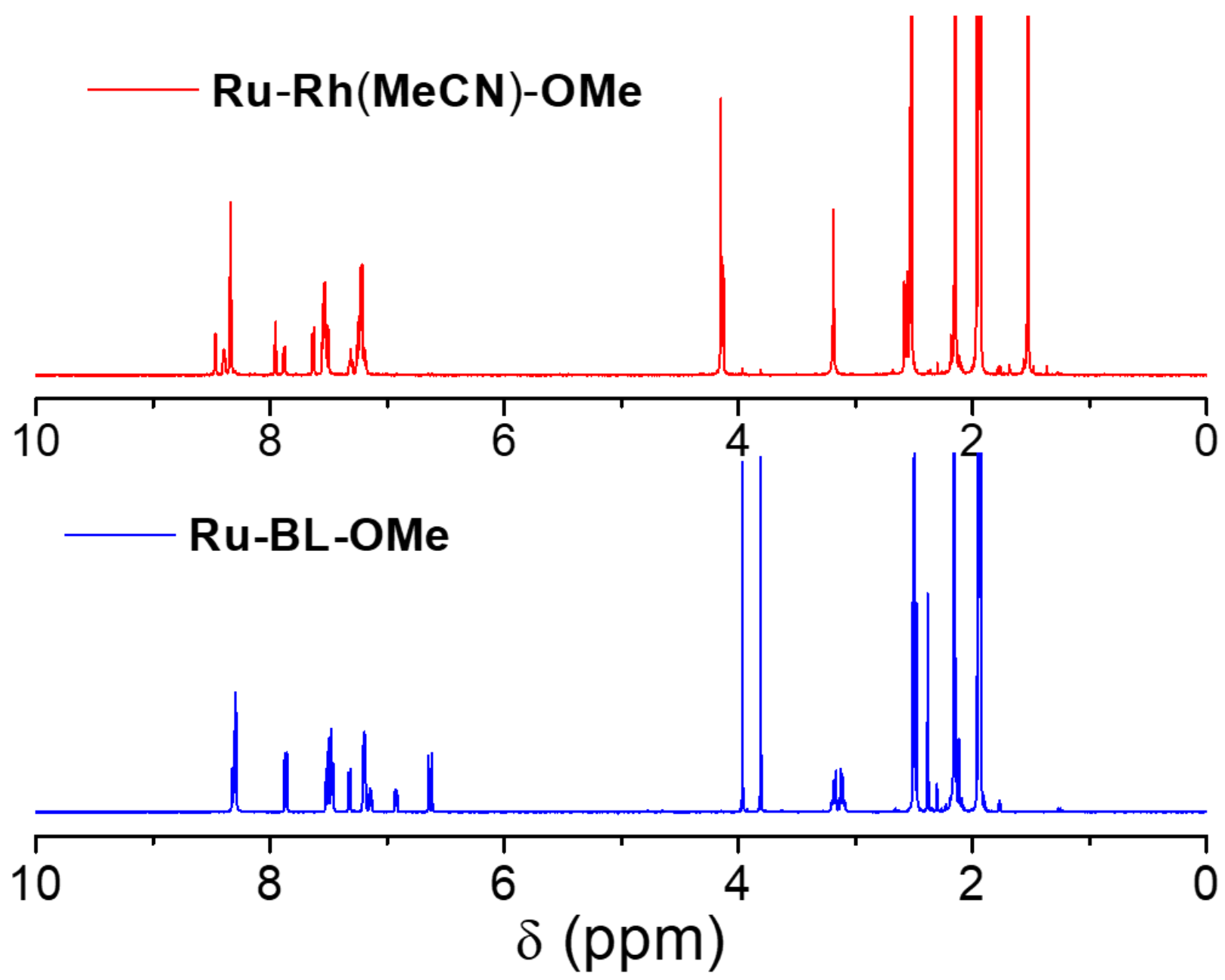

Figure S12: ${ }^{1} \mathrm{H}$ NMR spectrum of Ru-BL-OMe and $\mathbf{R u}-\mathbf{R h}(\mathbf{M e C N})-\mathrm{OMe}$ taken in $\mathrm{CD}_{3} \mathrm{CN}$. 


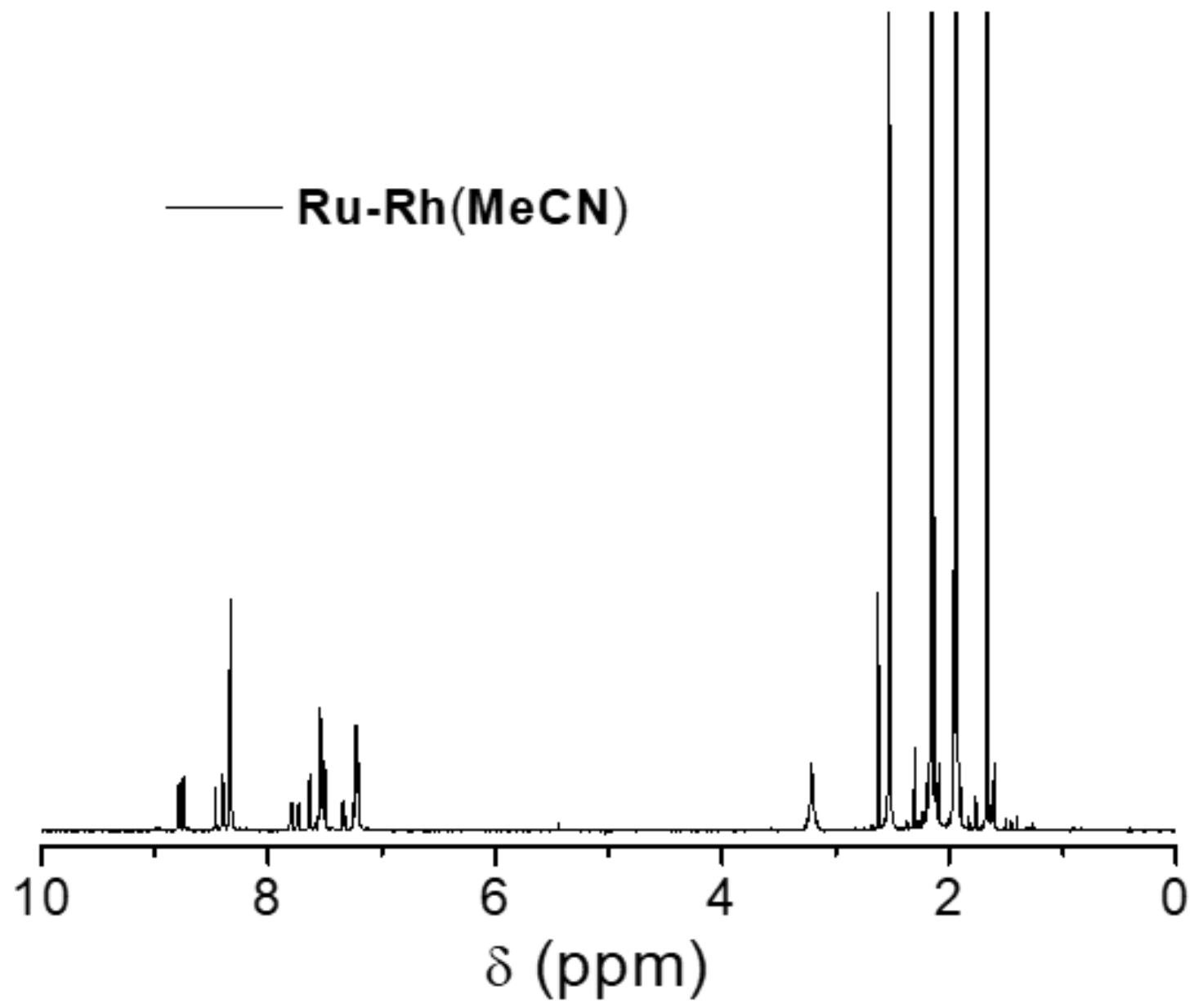

Figure S13: ${ }^{1} \mathrm{H}$ NMR spectrum of $\mathbf{R u}-\mathbf{R h}(\mathbf{M e C N})$ taken in $\mathrm{CD}_{3} \mathrm{CN}$ 


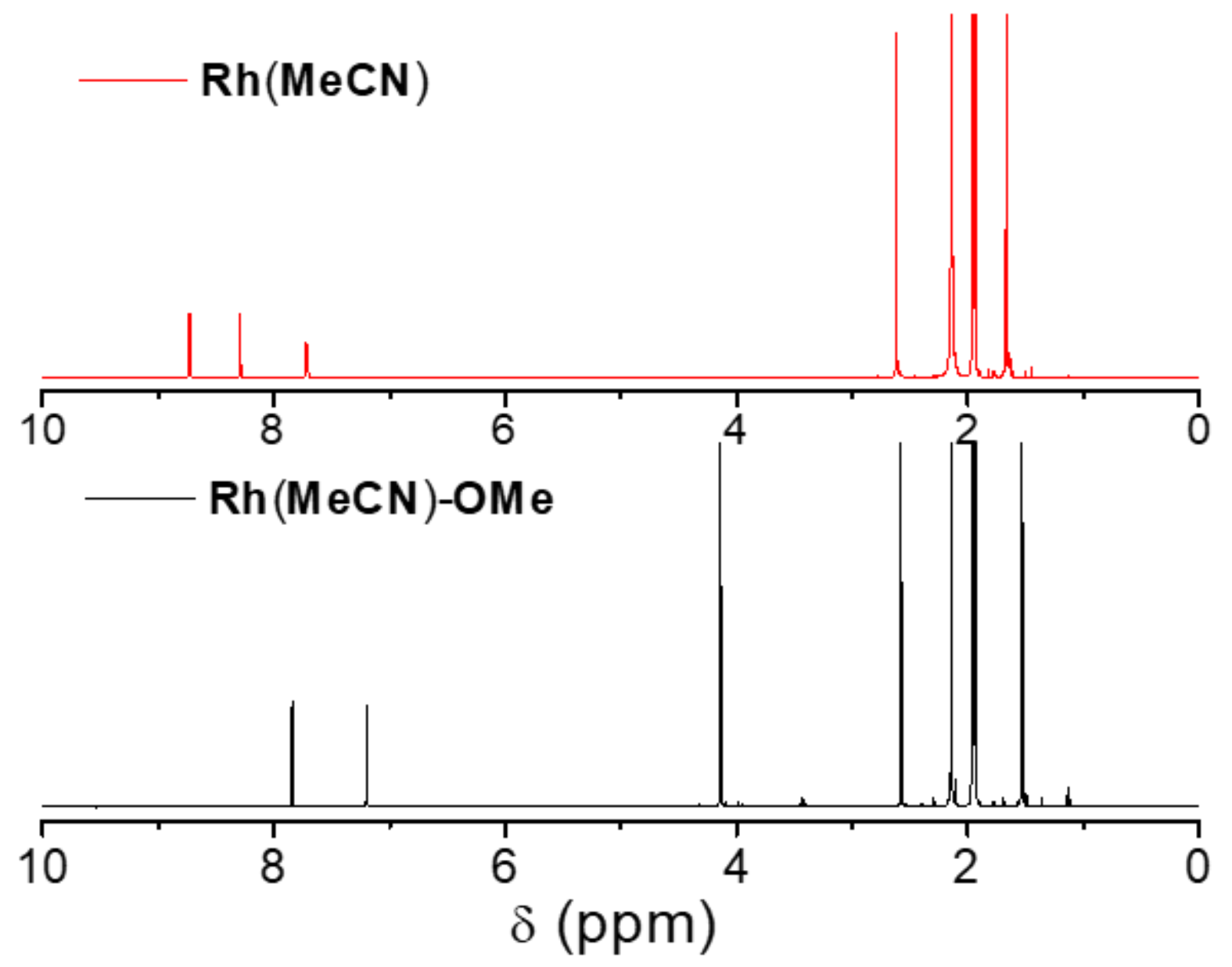

Figure S14: ${ }^{1} \mathrm{H}$ NMR spectrum of $\mathbf{R h}(\mathbf{M e C N})$ and $\mathbf{R h}(\mathbf{M e C N})-O M e$ taken in $\mathrm{CD}_{3} \mathrm{CN}$. 